\title{
Broadening the Scope of Peer-Mediated Intervention for Individuals with Autism Spectrum Disorders
}

\author{
Mateusz Płatos $^{1} \cdot$ Kinga Wojaczek $^{1}[0$ \\ Published online: 8 December 2017 \\ (C) The Author(s) 2017. This article is an open access publication
}

\begin{abstract}
Peer-mediated intervention (PMI) is most commonly defined as a treatment approach that engages typically developing peers to teach children with autism spectrum disorders (ASD) social skills and increase their social interactions, mainly in a school setting. In this letter, we address the limitations of such understanding of PMI and review the arguments for broadening its scope. In particular, we argue that there is a critical need for research on PMI that focuses on friendship, social participation, and well-being of adolescents and adults with ASD, as well as engages peers in the community settings. In conclusion, we provide a description of a befriending scheme for individuals with ASD to inspire future research and guidelines on PMI.
\end{abstract}

Keywords Autism spectrum disorders $\cdot$ Peer-mediated intervention $\cdot$ Befriending $\cdot$ Adolescent $\cdot$ Adult $\cdot$ Friendship

Peer-mediated intervention (PMI) is a set of practices in which typically developing peers are selected, trained, and supervised to teach or support individuals with autism spectrum disorders (ASD). With over 60 experimental studies published to date (Chan et al. 2009; Chang and Locke 2016; Watkins et al. 2015), PMI is considered one of the most supported and recommended evidence-based practices (EBPs) for children with ASD (Reichow and Volkmar 2010; Wang et al. 2011; Wong et al. 2015). Yet, in this letter we would like to draw attention to significant gaps in research on PMI and propose three extensions of its scope to include: (a) outof-school interventions that broaden social environments in which PMI can be provided, (b) adolescents and adults with ASD as a target group of PMI, and (c) befriending schemes involving procedures and outcomes related to friendship, social participation, and well-being. As we argue, those additions to PMI are well-matched with current findings on limitations of available treatments and unmet needs of individuals with ASD. These propositions are exemplified by a description of a befriending scheme for adolescents and

Mateusz Płatos

mateusz.platos@psych.uw.edu.pl

$\checkmark$ Kinga Wojaczek

kinga.wojaczek@psych.uw.edu.pl

1 Faculty of Psychology, University of Warsaw, Stawki Str. 5/7, 00-183 Warsaw, Poland adults with ASD—Peer Volunteers 'Mary and Max'-that has been developed in Poland.

\section{Extensions of Peer-Mediated Intervention}

Since the first studies on PMI in the late 1970s (Strain et al. 1979), schools and preschools have been a natural setting to provide PMI, ranging from settings in general education classes (Katz and Girolametto 2013) to schoolyards (Kasari et al. 2012) and secluded school facilities (Ganz et al. 2012). Given that school is a primary context for children to socialize with peers, schools seem a good place to implement PMI. The question remains, however, if effects of PMI generalize also to different settings, namely, out-of-school environments, such as extracurricular activities, playground, or hanging out with peers.

Considering difficulties of individuals with ASD in adapting to novel and unstructured situations (Hauck et al. 1995), narrow range of interests (APA 2013) and deficits in executive functions (Rosenthal et al. 2013), informal social and leisure activities may be particularly hard for them to participate. Research suggests that out-of-school participation of children with ASD is limited in a range of activities, social partners, and locations, compared to typically developing children, but differences are more pronounced in informal activities than formal ones (Hilton et al. 2008). A study by Shattuck et al. (2011) showed that about half of adolescents 
with ASD never see friends after school, are never called by friends, or invited to social activities, and the rates of social participation in their case are substantially lower than in other disability groups. Hence, PMI should encompass out-of-school activities, both organized and unorganized that would provide individuals with ASD environment-specific skills and experiences (e.g. going to the cinema with friends) that cannot be replicated in the school environment.

The second proposed extension of research on PMI concerns the inclusion of adolescents and adults with ASD as its target groups. Out of 42 studies on PMI reviewed by Chan et al. (2009) none referred to participants older than 13 years and only a few more recent case studies (Hughes et al. 2013; Ness 2013) bridge that gap. That coincides with the general scarcity of EBPs for adolescents and adults with ASD (Reichow and Volkmar 2010; Shattuck et al. 2012). However, there are many areas of adolescent and adult functioning in which specifically PMI could provide significant support. From early adolescence the role of friendship grows as a platform for the development of interpersonal competence and intimacy (Buhrmester 1990) and a preparation for romantic relationships (Connolly et al. 2000). It is not surprising that, due to their social difficulties, adolescents with ASD struggle to achieve high social status in a peer group (Symes and Humphrey 2010) and maintain friendships (Orsmond et al. 2004), which results in loneliness (Bauminger et al. 2003), sense of exclusion (Wainscot 2008), and high rates of bullying (Kloosterman et al. 2013), as well as high prevalence of anxiety, depression (Strang et al. 2012), and suicidal ideation (Mayes et al. 2013) in that group. Applying PMI to foster peer relations and friendship in adolescents with ASD could be a preventive measure against many of these negative outcomes (Bradley 2016).

The third and last proposed extension of research on PMI concerns its core procedures, aims, and intended outcomes. We argue that current focus of PMI for individuals with ASD on teaching social skills limits the potential of peer involvement. Teaching new skills is considered only one type of relationship-based voluntary schemes, the type usually referred to as 'mentoring'. The other end of the continuum of that broad category of schemes is represented by 'befriending' programs, that are focused on building supportive, friendship-like relationships, involving participation in joint pleasurable activities and conversations about common interests, but also some level of disclosure and emotional support (Thompson et al. 2016). Such a definition does not imply that the transfer of skills is not a goal and does not occur in befriending programs, but that transfer is embedded in a long-term, reciprocal relationship. Moreover, a different kind of skills is taught in befriending relationships, namely, friendship skills. The recognition that friendship requires some specific social skills is reflected in the emergence of evidence-based friendship trainings (Laugeson and Frankel 2010). However, we argue that learning friendship skills must involve the experience of at least some qualities of friendship - such as shared enjoyment, emotional bond, equality, and mutuality - in the context of a long-term relationship. For example, it is hard to learn how to manage jealousy of a friend without experiencing that feeling in a real-life situation. Therefore, we propose that befriending relationship can be a basis for socially and ecologically valid intervention that would teach individuals with ASD friendship skills generalizable to non-facilitated friendships.

While befriending schemes can serve as viable means of teaching individuals with ASD friendship skills, this should not be regarded as the only, and perhaps, the most important aim of such intervention. Befriending programs are widespread in mental health services, aimed at reducing loneliness, isolation, and affective symptoms in vulnerable populations (Thompson et al. 2016). As noted in a comprehensive review of EBPs by Wong et al. (2015), interventions for individuals with ASD rarely target their emotional well-being. We propose that providing a person with ASD with a stable, supportive, and meaningful relationship with a peer can attenuate some negative emotional outcomes linked to social exclusion of adolescents and adults with ASD, as well as increase their level of self-competence and social participation.

Lastly, research suggests not only a need of many individuals with ASD to have friends (Eaves and Ho 2008; Mazurek 2014; O'Hagan and Hebron 2017) but also a clear need for befriending services, as can be illustrated with data from three countries. A large-scale survey undertaken in England by the National Autistic Society (Rosenblatt 2008) showed that $33 \%$ of adults with ASD $(\mathrm{N}=1.179)$ would like to participate in a befriending scheme, while only $5 \%$ have it provided. In an Australian survey (Autism Spectrum Australia 2012) of high-functioning adults with ASD, about $35 \%$ of respondents $(\mathrm{N}=313)$ declared an unmet need for a mentor or befriender, while $28 \%$ already had access to mentoring or befriending support. Finally, a survey of adolescents and adults with ASD in Poland (Płatos et al. 2016), indicated that $43 \%$ of respondents $(\mathrm{N}=117)$ would like to participate in a befriending scheme. Moreover, $49 \%$ of parents in the English sample and $77 \%$ of parents in the Polish sample believed that their adolescent or adult child would benefit from befriending. Together, these results indicate that befriending services are greatly needed by individuals with ASD.

\section{Peer Volunteers 'Mary and Max'}

The above propositions of extending the scope of PMI will be exemplified by the description of Peer Volunteers 'Mary and Max'-PMI that has been developed in Poland since 
2012. Peer Volunteers 'Mary and Max' is a manual-based befriending scheme for high-functioning adolescents (from 12 years old) and adults with ASD (that we refer to as 'participants'). The focus of the program is to facilitate the oneto-one relationship between a participant and a volunteer, based on their common interests and joint leisure activities. The aim of arranging such a relationship is to provide a person with ASD a positive, supportive experience associated with a peer, enhance his or her self-perceived interpersonal competence, and increase social participation, thereby decreasing the sense of loneliness and isolation.

The key element of the program is the process of recruitment, selection, and matching of participants and volunteers. This process aims at (a) finding individuals with ASD who have intrinsic motivation to have a friend and spent time together, (b) finding peers who present high motivation to volunteer, good social skills, and emotional maturity, (c) matching participants and volunteers into pairs on the basis of their common interests, preferred activities, age, and area of living. The successful matching is the precondition for a safe, self-motivated, and enjoyable relationship the program is to facilitate. Before the program starts, volunteers undergo a 2-day training based on experiential learning that helps them understand the needs of people with ASD and their role as volunteers.

The core of the program consists in one-to-one, weekly get-togethers of a participant and a volunteer that involve various shared activities, planned and chosen by both sides. Those get-togethers are unsupervised either by professionals or parents and are held mainly in the public (e.g. in a park, a cinema, or a café), enhancing participants' access to the community life. Both participants and volunteers receive professional support in maintaining the relationship, provided by a psychologist who is assigned to the dyad throughout the program. The psychologist holds monthly individual consultations with the participant and the volunteer, working on their initiative, motivation, planning and organizing of get-togethers, expressing emotions, and essentially on the mentalizing skills. Eventually, the psychologist helps participants and volunteers decide whether they want to continue their relationship outside the scheme or resolve it in a gradual and supported process. Although evolving a befriending relationship into a friendship is not the aim of the scheme, most participants and volunteers express their willingness to do it, thus the psychologist's role is to help them make such a transition and take full responsibility for the relationship.

\section{Conclusions}

In this short article we argued that the scope of PMI should not be limited to teaching children with ASD social skills in a school setting. Although this type of PMI should certainly be continued and developed, we presented evidence that it would be beneficial to include peers in the support of adolescents and adults with ASD in the community and using befriending schemes to enhance their social participation and well-being. Importantly, the need for such services is clearly expressed by individuals with ASD themselves. Where those services have already existed, they should be backed by empirical research to inform international guidelines and EBP for PMI.

Author Contributions MP and KW conceived and structured the content of the article. MP with a help of KW drafted the manuscript. Both authors reviewed the manuscript critically and approved the final version.

Open Access This article is distributed under the terms of the Creative Commons Attribution 4.0 International License (http://creativecommons.org/licenses/by/4.0/), which permits unrestricted use, distribution, and reproduction in any medium, provided you give appropriate credit to the original author(s) and the source, provide a link to the Creative Commons license, and indicate if changes were made.

\section{References}

American Psychiatric Association. (2013). Diagnostic and statistical manual of mental disorders: DSM-5. (5th edn.). Arlington VA: American Psychiatric Association.

Autism Spectrum Australia (Aspect). (2012). We belong: Investigating the experiences, aspirations and needs of adults with Asperger's disorder and high functioning autism. Sydney: Autism Spectrum Australia.

Bauminger, N., Shulman, C., \& Agam, G. (2003). Peer interaction and loneliness in high functioning children with autism. Journal of Autism and Developmental Disorders, 33(5), 489-507.

Bradley, R. (2016). "Why single me out?” Peer mentoring, autism and inclusion in mainstream secondary schools. British Journal of Special Education, 43(3), 272-288.

Buhrmester, D. (1990). Intimacy of friendship, interpersonal competence, and adjustment during preadolescence and adolescence. Child Development, 61(4), 1101-1111.

Chan, J. M., Lang, R., Rispoli, M., O’Reilly, M., Sigafoos, J., \& Cole, H. (2009). Use of peer-mediated interventions in the treatment of autism spectrum disorders: A systematic review. Research in Autism Spectrum Disorders, 3(4), 876-889.

Chang, Y. C., \& Locke, J. (2016). A systematic review of peer-mediated interventions for children with autism spectrum disorder. Research in Autism Spectrum Disorders, 27, 1-10.

Connolly, J., Furman, W., \& Konarski, R. (2000). The role of peers in the emergence of heterosexual romantic relationships in adolescence. Child Development, 71(5), 1395-1408.

Eaves, L. C., \& Ho, H. H. (2008). Young adult outcome of autism spectrum disorders. Journal of Autism and Developmental Disorders, 38(4), 739-747.

Ganz, J. B., Heath, A. K., Lund, E. M., Camargo, S. P. H., Rispoli, M. J., Boles, M., \& Plaisance, L. (2012). Effects of peer-mediated implementation of visual scripts in middle school. Behavior Modification, 36(3), 378-398.

Hauck, M., Fein, D., Waterhouse, L., \& Feinstein, C. (1995). Social initiations by autistic children to adults and other children. Journal of Autism and Developmental Disorders, 25(6), 579-595. 
Hilton, C. L., Crouch, M. C., \& Israel, H. (2008). Out-of-school participation patterns in children with high-functioning autism spectrum disorders. American Journal of Occupational Therapy, 62(5), 554-563.

Hughes, C., Harvey, M., Cosgriff, J., Reilly, C., Heilingoetter, J., Brigham, N., ... Bernstein, R. (2013). A peer-delivered social interaction intervention for high school students with autism. Research and Practice for Persons with Severe Disabilities, 38(1), $1-16$.

Kasari, C., Rotheram-Fuller, E., Locke, J., \& Gulsrud, A. (2012). Making the connection: Randomized controlled trial of social skills at school for children with autism spectrum disorders. Journal of Child Psychology and Psychiatry and Allied Disciplines, 53(4), 431-439.

Katz, E., \& Girolametto, L. (2013). Peer-mediated intervention for preschoolers with ASD implemented in early childhood education settings. Topics in Early Childhood Special Education, 33(3), 133-143.

Kloosterman, P. H., Kelley, E. A., Craig, W. M., Parker, J. D., \& Javier, C. (2013). Types and experiences of bullying in adolescents with an autism spectrum disorder. Research in Autism Spectrum Disorders, 7(7), 824-832.

Laugeson, E. A., \& Frankel, F. (2010). Social skills for teenagers with developmental and autism spectrum disorders: The PEERS treatment manual. New York: Routledge.

Mayes, S. D., Gorman, A. A., Hillwig-Garcia, J., \& Syed, E. (2013). Suicide ideation and attempts in children with autism. Research in Autism Spectrum Disorders, 7(1), 109-119.

Mazurek, M. O. (2014). Loneliness, friendship, and well-being in adults with autism spectrum disorders. Autism, 18(3), 223-232.

Ness, B. M. (2013). Supporting self-regulated learning for college students with Asperger syndrome: Exploring the "Strategies for College Learning" model. Mentoring \& Tutoring: Partnership in Learning, 21(4), 356-377.

O'Hagan, S., \& Hebron, J. (2017). Perceptions of friendship among adolescents with autism spectrum conditions in a mainstream high school resource provision. European Journal of Special Needs Education, 32(3), 314-328.

Orsmond, G. I., Krauss, M. W., \& Seltzer, M. M. (2004). Peer relationships and social and recreational activities among adolescents and adults with autism. Journal of Autism and Developmental Disorders, 34(3), 245-256.

Płatos, M., Gocłowska, K., Wojaczek, K., Woźniak-Rekucka, P., Zawisny, A., \& Pisula, E. (2016). Sytuacja młodzieży i dorosłych $\mathrm{z}$ autyzmem w świetle sondażu ogólnopolskiego. In M. Płatos (Ed.), Ogólnopolski Spis Autyzmu. Sytuacja młodzieży i dorostych z autyzmem w Polsce (pp. 64-66). Warszawa: Stowarzyszenie Innowacji Społecznych 'May i Max'.

Reichow, B., \& Volkmar, F. R. (2010). Social skills interventions for individuals with autism: Evaluation for evidence-based practices within a best evidence synthesis framework. Journal of Autism and Developmental Disorders, 40(2), 149-166.
Rosenblatt, M. (2008). I exist: The message from adults with autism in England. London: National Autistic Society.

Rosenthal, M., Wallace, G. L., Lawson, R., Wills, M. C., Yerys, B. E., \& Kenworthy, L. (2013). Impairments in real world executive function increase from childhood to adolescence in autism spectrum disorders. Neuropsychology, 27(1), 13-18.

Shattuck, P. T., Orsmond, G. I., Wagner, M., \& Cooper, B. P. (2011) Participation in social activities among adolescents with an autism spectrum disorder. PLOS ONE, 6(11), e27176.

Shattuck, P. T., Roux, A. M., Hudson, L. E., Taylor, J. L., Maenner, M. J., \& Trani, J.-F. (2012). Services for adults with an autism spectrum disorder. The Canadian Journal of Psychiatry, 57(5), 284-291.

Strain, P. S., Kerr, M. M., \& Ragland, E. U. (1979). Effects of peermediated social initiations and prompting/reinforcement procedures on the social behavior of autistic children. Journal of Autism and Developmental Disorders, 9(1), 41-54.

Strang, J. F., Kenworthy, L., Daniolos, P., Case, L., Wills, M. C., \& Wallace, G. L. (2012). Depression and anxiety symptoms in children and adolescents with autism spectrum disorders without intellectual disability. Research in Autism Spectrum Disorders, 6(1), 406-412.

Symes, W., \& Humphrey, N. (2010). Peer-group indicators of social inclusion among pupils with autistic spectrum disorders (ASD) in mainstream secondary schools: A comparative study. School Psychology International, 31(5), 478-494.

Thompson, R., Valenti, E., Siette, J., \& Priebe, S. (2016). To befriend or to be a friend: A systematic review of the meaning and practice of "befriending" in mental health care. Journal of Mental Health, 25(1), 71-77.

Wainscot, J. J. (2008). Relationships with peers and use of the school environment of mainstream secondary school pupils with Asperger syndrome (high-functioning autism): A case-control study. Revista Internacional de Psicología Y Terapia Psicológica, 8(1), 25-38.

Wang, S. Y., Cui, Y., \& Parrila, R. (2011). Examining the effectiveness of peer-mediated and video-modeling social skills interventions for children with autism spectrum disorders: A meta-analysis in single-case research using HLM. Research in Autism Spectrum Disorders, 5(1), 562-569.

Watkins, L., O’Reilly, M., Kuhn, M., Gevarter, C., Lancioni, G. E., Sigafoos, J., \& Lang, R. (2015). A review of peer-mediated social interaction interventions for students with autism in inclusive settings. Journal of Autism and Developmental Disorders, 45(4), 1070-1083.

Wong, C., Odom, S. L., Hume, K. A., Cox, A. W., Fettig, A., Kucharczyk, S., ... Schultz, T. R. (2015). Evidence-based practices for children, youth, and young adults with autism spectrum disorder: A comprehensive review. Journal of Autism and Developmental Disorders, 45(7), 1951-1966. 